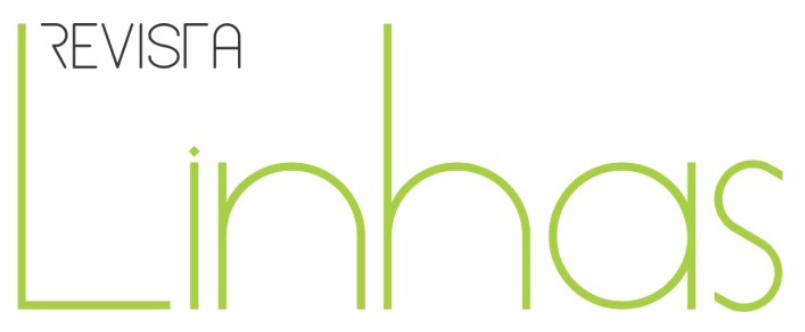

\title{
Os bebês e a constituição da linguagem: uma abordagem teórica, histórica e etimológica
}

\begin{abstract}
Resumo
Este artigo é parte de uma pesquisa de mestrado concluída no ano de 2011 e tem por objetivo apresentar o conceito de infância instituído socialmente e a relação com a constituição da linguagem entre os bebês. Para sua estruturação, recorri à etimologia do conceito de infância, assim como a uma breve revisão historiográfica que me permitisse, ainda que de maneira breve, observar as imagens de infância produzidas ao longo da modernidade. A História e a Psicologia Histórico-Cultural são trazidas neste estudo para situar a infância e as crianças pequenas social, histórica e culturalmente. Busquei ainda apresentar diálogos estabelecidos entre a Pedagogia, a Sociologia da Infância e a Filosofia da Linguagem (Bakhtin) para compreender a constituição da linguagem entre os bebês no contexto coletivo da Educação Infantil. Da mesma forma, procurei assinalar a importância da pesquisa com bebês para o campo da Educação Infantil, admitindo que conhecer a constituição de sua linguagem pode ser um caminho para aprofundar o conhecimento a respeito deles e romper com a ideia de que infância é sinônimo de incompletude.
\end{abstract}

Palavras-chave: Bebês. Infância. Linguagem. Modernidade.

\author{
Joselma Salazar de Castro \\ Doutoranda em Educação pela \\ Universidade Federal de Santa \\ Catarina - UFSC. \\ josalazar@ig.com.br
}

\footnotetext{
Para citar este artigo:

CASTRO, Joselma Salazar de. Os bebês e a constituição da linguagem: uma abordagem teórica e etimológica. Revista Linhas, Florianópolis, v. 14, n. 27, jul./dez. 2013. p. 281 - 300
} 


\title{
Babies and the constitution of the language: a theoretical, historical and etymological approach
}

\begin{abstract}
This article is part of a research completed in 2011 and aims to present the concept of childhood and the relationship socially established within the constitution of language among babies. For its structure, I resorted to the etymology of the concept of childhood, as well as a brief historiographical revision that would allow me, even briefly, to watch the images of childhood produced throughout modernity. History and Historical-Cultural Psychology are brought to situate this study childhood and young children socially, historically and culturally. I sought also to present dialogues between Pedagogy, Sociology of Childhood and the Philosophy of Language (Bakhtin) to understand the constitution of language among babies in the collective context of early childhood education. Likewise, I focused to the importance of a research with babies to the field of Early Childhood Education. Admitting that knowing the structure of their language can be a way to deepen the knowledge about them and to break with the idea that childhood is synonymous of incompleteness.
\end{abstract}

Keywords: Babies. Childhood. Language. Modernity. 


\section{Introdução}

O presente artigo é resultante de uma pesquisa de mestrado que versou sobre a constituição da linguagem entre os bebês, de sete meses a um e meio de idade. Para que eles se pudessem constituir como sujeitos principais deste estudo e para os compreender como atores sociais, foi necessário buscar subsídios teóricos na Sociologia da Infância. Da mesma forma, procurei identificar o modo como a infância vem sendo institucionalizada desde o início da industrialização, principalmente a partir do início do século XX e como, em meio a mudanças (globais) socioeconômicas, surgiu a idade bebê.

Para justificar a importância desse estudo, além de conhecê-los melhor, busquei relacionar seus jeitos de ser com a constituição da linguagem e a relação desse processo com a etimologia da palavra infância.

Segundo o Dicionário Houaisss (2009), infância, etimologicamente, significa, primeiramente, o período do desenvolvimento do ser humano que vai do nascimento ao início da adolescência, conhecida como meninice, puerícia; em segunda instância, o conjunto das crianças e, por fim, o começo, o nascimento (de algo). Logo, é possível localizar a palavra infante traduzida como criança, menino, na perspectiva relativa à infância; infantil, que não fala, que tem pouca idade, novo, pequeno, criança, incompleta.

Como podemos observar, o conceito e o que remete à palavra infante carregam consigo um sentido, acima de tudo, de incompletude, com ênfase no pequeno, no que não fala, no novo e no de pouca idade. Ademais, é um conceito discursivo - "a infância é uma personagem oculta" - que aparece na retórica, nos ideais de um determinado momento histórico. Assim, institui-se pela representação e pelo imaginário social como segmento de menor importância (BECCHI, 1994).

A origem do termo in-fans (do latim), vem constituída do poder da palavra que se quer alcançar e não somente do fato de o sujeito ser incapaz de verbalizar a fala, mas principalmente de alguém que precisa adquirir condições para tal. Becchi (1994), ao referir-se ao poder do exercício da fala, assevera:

Um primeiro e fundamental sinal de tal domínio é que o não-adulto, em boa parte das línguas neolatinas e também em inglês, se apresenta sob 
forma de metonímia: de fato, infante deriva de in-fari (= que não pode falar) onde uma parte (a incompetência lingüística) designa o todo. E não se trata somente de uma metonímia pura e simples, porque é expressa em negativo (infanzia), é uma metonímia com valor de litotes (BECCHI, 1994, p. 64).

Neste sentido, a autora chama a atenção para a "metonímia com valor de litotes" intrínseca ao termo infância, que representa a figura de uma palavra fora do seu contexto semântico normal; o termo litotes sugere a ideia de negação da retórica ao seu contrário. Neste caso, infância existe a partir do discurso ideológico formado acerca do termo, mas, de modo irônico, transparecendo a tenuidade desse conceito. A autora remonta à constituição da retórica da infância, a partir de um mosaico inspirado por várias peças do cenário socioideológico que, dialeticamente, se fazem presentes na história da humanidade:

[...] o jogo metafórico da página de infância inspira alguns fatos onde ele se revela muito sutil e sinuoso porque não se trata somente das dimensões da argumentação, de locuções de grande relevância poética, mas principalmente de substanciosas obras ideológicas que tocam e colocam em questão não só representações e imagens do não-adulto, mas também os comportamentos e as práticas coletivas, institucionalizadas ou não, que o atravessam em todas as suas conexões (BECCHI, 1994, p. 66).

Pode-se iniciar um perfil histórico da infância rastreando também algumas imagens de infância, simbólicas, instituídas ao longo do tempo. Quando me refiro a imagens da infância, não me restrinjo ao caráter iconográfico de interpretação, que, para Panofsky (1979, p. 53) é "a descrição e classificação das imagens, assim como etnografia é a descrição e classificação das raças humanas; é um estudo limitado” [...], ou seja, “[...] que nos informa quando e onde temas específicos foram visualizados por quais motivos específicos." Procurei, acima de tudo, localizar e analisar os processos de constituição da infância por meio de bibliografias, já que a pesquisa não tinha qualquer relação com artes plásticas.

Percebi, ainda assim, a importância de compreender a construção do imaginário social sobre a infância e a relevância de alguns estudos sobre a temática. A autora Magali 
Reis, em sua pesquisa de doutoramento, explicou a relação da infância com o método iconográfico, fornecendo pistas para esta compreensão (REIS, 2007, p. 6):

Semântica e iconografia justapõem-se possibilitando a produção de sentidos. Num jogo de opostos os mal nascidos, sujeitos preexistentes na sociedade, figuram como objeto de preocupação, corpo frágil, inerte, ameaça, risco de mortalidade, sintoma social. Corpo a ser higienizado corpo a ser disciplinado de um lado. De outro lado, a criança bem comportada e livre das marcas visíveis da carência, da pobreza. A produção de imagens da criança obedece ao ritmo que é próprio da sociedade, no qual imagem e imaginário se compõem para veicular ideias através de pinturas, fotografias, ilustrações, caricaturas. Participam assim do fazer social operando na elaboração de um padrão, reforçando valores dominantes na sociedade de classes.

Para a autora, as imagens da criança são mais que traduções de uma determinada infância; são a impregnação da imagem política e do inconsciente social. São representações de análises realizadas pelos adultos de acordo com suas próprias interpretações. Com isso, estudar a infância por meio de imagens exige delinear a pesquisa ao encontro das concepções de infância que permeiam a sociedade e ir além da relação epistêmica dessa área; penetrar, de certo modo, no imaginário adultocêntrico para identificar o sentimento social de infância.

Feita esta breve incursão teórica, recorri ao início da modernidade a fim de identificar as representações socialmente constituídas em relação a bebês no período inicial da industrialização.

\section{A representação dos bebês na história da infância do século XX}

Diferentes pesquisas vêm abordando a infância como objeto de investigação, principalmente nas áreas da Psicologia, da Medicina, da Educação, da História, do Direito e, mais recentemente, da Sociologia da Infância. Os primeiros estudos surgiram da necessidade de conhecer a criança, momento em que esta passou a ser objeto de pesquisa pelas áreas das ciências médicas, humanas e sociais.

Uma análise relevante, com a história da criança e a relação de dever do Estado foi desenvolvida na obra Salvar corpos, forjar a razão, da autora portuguesa Manuela Ferreira 
(2000). O estudo, concomitantemente, revela as premissas da institucionalização da infância, principalmente no início do século anterior.

A representação que a autora encontra em Portugal ${ }^{1}$ entre o século XIX e o século XX está no centro de discussões, por vezes como criação do ideário humano e da sociedade. Numa perspectiva do vir a ser, a imagem da criança parece incorporar todas as esperanças do imaginário coletivo. Nesse contexto, fala-se de uma infância única, universal, com direitos a proteção e guarda. Ao mesmo tempo, porém, são alarmantes os índices de mortalidade, de violência contra a criança, fatos que, paradoxalmente, lhe negam os direitos apregoados pela retórica, mas tolhidos pela realidade.

O conceito e as concepções de infância "acabam por apenas adotar uma dada perspectiva; ficam ainda por esclarecer, para além das especificidades da infância, as suas particularidades, ou seja, em que é que as crianças são diferentes entre si, considerando a classe social, gênero, idade, etnia..." (FERREIRA, 2000, p. 9). Nessa perspectiva, a homogeneização da infância institui, pelos Direitos Humanos, um ideal de ser criança, furtando a heterogeneidade, as diferenças de classes, além de ocultar conflitos inerentes a essa categoria social.

Retomando os aspectos históricos, a partir das necessidades sociais e econômicas, reveladas no final do século XIX e início do século XX na sociedade industrial, as crianças passam a ser consideradas como instituição que necessita de cuidados. Assim, a Pediatria, área da Medicina, a elegeu como objeto a ser pesquisado de modo isolado; porém, ao debater os fatores que ocasionavam os altos índices de mortalidade e doenças nos primeiros anos de vida, esta área se confronta com suas próprias limitações, passando a compreender que "[...] a gênese dos problemas e a sua cura não se confinam ao campo restrito do biológico e médico [...]", mas se transpõem a um campo social e cultural (FERREIRA, 2000, p. 87).

Entretanto, mesmo com a constatação de que o aspecto biológico por si só não resolveria todos os problemas que atingiam a saúde física e mental da criança, a Medicina

\footnotetext{
${ }^{1}$ Autores que abordam a historiografia social da infância no Brasil apontam semelhanças com Portugal. Ver: DEL PRIORI, M. (1997); KUHLMANN JR., M. (1998).
} 
não saiu de cena; ao contrário, a Pediatria assumiu os estudos no aspecto biofisiológico de zero a doze anos -, centrando-se mais no desenvolvimento. Surge neste mesmo período, com destaque, a Puericultura, área que se preocupa em atender aos cuidados da criança, do período pré-natal à puberdade, em perspectiva global, visando a intervir e a questionar aspectos biossocioculturais.

Essa área da Medicina (Pediatria - Puericultura) foi eleita como a ciência médica ideal para orientar os cuidados que a família, principalmente a mãe, deveria ter com a criança, e intervir desde a primeira formação (gestação) até os três anos, assumindo, assim, o papel técnico dos saberes médicos, a higienização e o cuidado. É neste mesmo momento que também a Psicologia passa a atuar em integração com a Medicina, acrescentando mais um aspecto - o biopsicológico - ao campo científico de pesquisa.

Seguindo os avanços da sociedade moderna, caracterizada pelo fervor da industrialização e do desenvolvimento capitalista, constituída pela exigência de mão-deobra, escolarização e formação profissional, desencadeou-se, paralelamente, ao final de meados do século XX, a institucionalização da Sociologia da Juventude, para responder à demanda social de um grupo etário que interessava à sociedade, mas deixando de fora outra parcela não menos relevante, conforme denuncia Ferreira (2000, p.12):

\begin{abstract}
Efetivamente, olhando este campo, verifica-se que enquanto se constitui uma Sociologia da Juventude, sobretudo a partir dos anos 60, desencadeada em torno das problemáticas da sua entrada no mundo do trabalho, escolarização, formação profissional, desemprego, lazer e consumo, o mesmo não aconteceu relativamente a uma Sociologia da posição dos bebês e das crianças de 3 aos 11 anos, e das suas relações com os adultos e as outras crianças.
\end{abstract}

Por tal razão justifico, em certa medida, o interesse e a necessidade de pesquisas com os bebês, já que, historicamente, eles não são considerados ativos pela sociedade; quando muito, são considerados dependentes, porém sem produtividade cultural e econômica e apenas como um vir a ser, a pensar, a falar, a andar e, principalmente, a produzir bens econômicos.

Na perspectiva de romper com paradigmas socioemotivos e sociocognitivos nos estudos relacionados às crianças bem pequenas, Bondioli e Mantovani (1998) afirmam 
que estes devem superar a perspectiva da relação do apego, percebendo que investigálos sob a ótica da interação com os pares e na produção de culturas também pode ser promissor. As autoras assinalam que foi somente a partir dos anos 1970 que as crianças pequeninas começaram a ser percebidas como sujeitos com possibilidade social.

A partir dos anos de 1970 estudos acerca do desenvolvimento social da criança assinalam possibilidades de intencionalidade comunicativa [...] As crianças abaixo de três anos aparecem, por esses estudos, muito menos egocêntricas do que se pensava no passado e capazes de interagir adequadamente, de um ponto de vista social, com parceiros, adultos e coetâneos (BONDIOLI e MANTOVANI, 1998, p. 28).

Por longas décadas preponderou a invenção da idade "bebê" a partir das induções da medicina e das práticas higienistas, como preservação da espécie humana e erradicação das taxas elevadas de mortalidade infantil, induções segundo as quais os bebês eram concebidos pelo devir (PROUT, 2004).

Outro aspecto importante de se ressaltar é o relativo ao crescimento da industrialização, que definiu um novo papel para a mulher e a mãe, convergindo para transformações econômicas, ideológicas e culturais, que se traduziram na produção de objetos de consumo para um mais público consumidor, o da infância. Assim, nessa complexa transição histórica, social e econômica, os bebês passaram a ser provedores de consumo, tornando-se importantes na fomentação da economia mundial pela indústria de produtos especificamente destinados a eles.

Nesse vasto panorama de transformações sociais, segundo Ferreira (2000), a escola assume um papel fundamental no processo intencional de socialização, estabelecendo/mantendo distinções entre a idade biológica e a idade da razão. Com isso, bebês de zero a três anos recebiam atendimento voltado aos cuidados fisiológicos; a partir de sete anos, atingida a chamada idade da razão, deviam ser atendidas por um aparato cultural e intelectual de socialização e preparação para a vida adulta, já que médicos pesquisadores identificavam nas crianças de três a seis anos de idade indivíduos com competências físicas e com prováveis competências intelectuais, pois, se a criança já caminhava, falava, expressava sentimentos e desejos possíveis de serem compreendidos, possuía, logicamente, condições básicas para se tornar objeto de estudo. 
Esta concepção de infância, instituída por interesses sociais e econômicos, primeiramente como forma de preservar a espécie humana, depois como objeto de descobertas para algumas áreas do conhecimento, que triunfaram a partir das investigações sobre as crianças, e, por fim, como objeto produtor de consumo, afirma a imprescindibilidade da escola como instituição socializadora, respondendo aos interesses da sociedade moderna, principalmente por suprir o papel do cuidado materno, já que as mães são liberadas também como mão-de-obra. Os primeiros anos da infância, assim, são definidos como artefato pedagógico, conforme indicam Chamboredon e Prévot (1986):

A análise da gênese da definição social da primeira infância como objeto pedagógico e das condições sociais da difusão desta definição é condição prévia para funções preenchidas pela escola maternal para as diferentes classes sociais, funções que podem ser evidenciadas construindo-se $o$ sistema de relações mantidas pela instituição com as formas de transmissão cultural nas diferentes classes (CHAMBOREDON e RÉVOT, 1986, p. 33).

Desta forma, pode-se anunciar que a concepção acerca dos bebês, em grande parte do século XX, se definiu pela necessidade de cuidados físicos, enquanto as outras crianças, da segunda infância (três a seis anos), necessitavam de cuidados psicológicos e culturais.

Pode-se então perguntar se as crianças têm idades específicas para ser cuidadas e ter o repertório cultural ampliado. A resposta parece provir da constatação de que o ser humano, em toda a dimensão de sua vida, necessita de cuidados físicos e psicológicos, como igualmente e em todas as suas idades, tem direitos à cultura, ao lazer, à política, à arte, ao convívio com a natureza. Apesar dessa dedução, a história tem mostrado que esses direitos são negados às crianças, de modo especial como/quando lhes é negado o direito de viver a infância em sua plenitude.

Isto representa, como analisou Ferreira (2000), que na perspectiva moderna de uma sociedade letrada, a infância é reduzida a sinônimo de criança-aluno, tendo que assumir, neste período de vida, um padrão universal. Não obstante, a infância não se inicia a partir dos sete anos de idade, a chamada idade da razão, nem simplesmente por já ter condições de ser escolarizada. Como e onde fica a outra parte da infância que 
antecede esse período? Novamente, por não se considerar produtiva, nem potencializada, é uma infância negada.

Pode-se assinalar que as primeiras críticas sobre a infância, abalizadas pelos teóricos da História da Infância, partiram principalmente da obra de Philippe Ariès (1979), História social da criança e da família, que mostra que as transformações pelas quais os adultos concebem a criança podem ser constatadas desde o final da Idade Média (século $\mathrm{XVI}$ ). Todas essas transformações ocorreram, como foi visto anteriormente, por uma série de institucionalizações, como a da escola, a da reorganização no interior da família e o estabelecimento de normas que padronizaram as intervenções dirigidas a esta parcela in- fans - da população.

Segundo Warde (2007), pesquisadores como Koops, 1996; Polakow, 1992; Pollock, 1987 a, 1987 b; Schultz, 1995; Woods, $2003^{2}$ criticam a obra de Ariès por entenderem haver falta de rigor metodológico no momento de comprovar as hipóteses, já que suas investigações foram realizadas a partir do método iconográfico, além de não incluírem as camadas desfavorecidas da população, pois abordou, mais precisamente partindo do século XV, a burguesia. No entanto, é importante rever que o autor introduziu uma nova perspectiva nos estudos acerca dos aspectos históricos e sociais da infância. Assim, apesar das divergências de posicionamento em torno de sua pesquisa, muitos estudiosos ainda se utilizam das categorias de análise por ele indicadas.

Philippe Ariès (1981) traduziu a imagem de infância, representada ao longo da história da humanidade por um sentimento profano e, ao mesmo tempo, sagrado, que, de qualquer modo, marginaliza os agentes dessa categoria geracional mesmo quando reaparece como foco principal na institucionalização e afirmação da escola:

La infancia ha permanecido en la sombra durante bastantes siglos. No es, pues, sorprendente verla reaparecer en la época en la que la cultura escrita, y por consiguiente la escuela, reconquista sus derechos y se difunde a partir del siglo XII. Ciertamente, en la escultura gótica los ángeles, como el de Reimis, y los obispos son casi siempre jóvenes adultos; la vejez parece reservada a los santos del Antiguo y Nuevo Testamento, a los personajes del otro mundo. En cuanto a la infancia, queda reservada para Jesús niño, pero éste ya es un auténtico niño, a

\footnotetext{
${ }^{2}$ Para aprofundar o estudo acerca da crítica desenvolvida por estes autores a Ariès, ler Warde (2007).
} 
veces envuelto en pañales, y su madre, reciente el parto, se inclina sobre él y lo acaricia con afecto: el Jesús niño del arte gótico desempeña el papel del buer bimulus de Catulo. Indica que se ha superado la etapa, que se redescubre la infancia. La forma pequeña incapaz de crecer se ha convertido en una especie de monstruo que en breve será objeto de diversión en las cortes principescas, al igual que los animales exóticos y raros: el enano ${ }^{3}$ (ARIÈS, 1979, p. 11).

Dessa forma, foi possível reconhecer na História da Infância as diferentes imagens ilustradas nos últimos séculos acerca das crianças pequeninas. Em contrapartida, outras áreas do conhecimento, embora recentes, vêm inaugurando uma tomada de posição diferente nas pesquisas com crianças, tendo como princípio pesquisá-la a partir dela mesma, considerando suas ações e seus mundos de vida, considerando-a também como agente cultural e histórico, com vistas a romper com a visão adultocêntrica, permitindo, nas pesquisas, que a própria criança participe como sujeito ativo no processo e não apenas como objeto de estudos.

Para os autores Pinto e Sarmento (1997, p. 21), “[...] as culturas infantis não nascem no universo simbólico, exclusivo da Infância; este universo não é fechado - pelo contrário, é, mais do que qualquer outro, extremamente permeável, nem lhe é alheia a reflexividade global social". Sendo assim, a infância deve ser entendida como uma construção social, que vem apresentando problemáticas paradoxais. Ao mesmo tempo em que existe um olhar mais atencioso sobre os Direitos da Criança, continua crescendo o número de crianças em situação de precariedade social. E os bebês, o que é pensado para eles? As manifestações desses agentes de pouca idade são por acaso escutadas? O que se conhece das estratégias de sua comunicação, principalmente antes da fala?

\footnotetext{
${ }^{3} \mathrm{~A}$ infância ficou na sombra por longos séculos. Não surpreende vê-la reaparecer na época em que a cultura escrita, a da escola, portanto, em que conquista seus direitos e se difunde a partir séc. XII. Certamente, na escultura gótica, os anjos, como o de Reimis, e os bispos são quase sempre jovens adultos; a velhice parece reservada aos santos do Antigo e do Novo Testamento, personagens do outro mundo. Quanto à infância, é reservada ao menino Jesus, que já é um verdadeiro menino, mesmo que envolto em panos; sua mãe, inda que logo a seguir ao parto, já se inclina sobre ele e o acaricia afetuosamente: o menino Jesus da arte gótica desempenha o papel de puer bimulus (menino de dois anos) de Catulo. Isto significa a superação de uma etapa, ou seja, a redescoberta da infância. A forma pequena, ou a incapacidade de crescer, se converteu numa espécie de monstro que em breve será objeto de diversão nas cortes principescas, igual aos animais exóticos e raros: o anão. (ARIÈS, 1979, p. 11; tradução do revisor)
} 


\section{A constituição da linguagem entre os bebês: um breve diálogo com a Sociologia da Infância}

A Sociologia da Infância vem firmando, a respeito da criança, uma concepção de ator social, competente na apropriação dos atos sociais de dado contexto, respondendo por eles. Este novo segmento propicia que conheçamos as crianças a partir delas próprias, como afirma Sarmento (2005, p. 363): “A infância é concebida como uma categoria social do tipo geracional por meio da qual se revelam as possibilidades e os constrangimentos da estrutura social." Neste sentido, os bebês pertencem a esta mais nova categoria, mas com peculiaridades que não podem ser assumidas de forma comum, nem generalizadas no contexto da pequena infância.

De acordo com a concepção do autor acima citado, compreendo que a infância, enquanto categoria geracional, deve ser considerada como "uma categoria estrutural relevante na análise dos processos de estratificação social e na construção das relações sociais" (SARMENTO, 2005, p. 363); portanto, não deve ser definida de modo generalizado e simplista. Aspectos sociais, culturais, étnicos, religiosos e econômicos diferenciam uma infância de outra.

A aproximação a contextos coletivos de educação em que estão inseridos os bebês, caso do presente estudo, foi importante para conhecer as particularidades expressas por eles e suas múltiplas estratégias de comunicação. Este processo exigiu um olhar auscultativo para apreender o modo como eles se manifestam. A auscultação ${ }^{4}$ envolve, acima de tudo, a compreensão do modo de comunicação do outro, uma comunicação por vezes ausente da linguagem oral e traduzida por outras enunciações.

As estratégias de comunicação e as ações de linguagens entre os bebês são meios que as crianças bem pequeninas têm para manifestar a apropriação que fazem com o mundo e com a cultura, travando relações sociais, tornando-se sujeitos ativos com capacidade de interagir com outros sujeitos de diferentes idades e com seus pares. É nessa sua interação do bebê com o mundo que o cerca que o processo dialógico se

\footnotetext{
${ }^{4}$ Ver Rocha (2010), em Diretrizes Educacionais Pedagógicas para a Educação Infantil da Rede Municipal de Ensino de Florianópolis.
} 
manifesta e ganha importância, ao entender que sua linguagem traduz mais do que simples desejos e necessidades.

Conforme Vygotsky (1989), a essência biológica do funcionamento psicológico necessita da inserção do sujeito em um meio social e cultural específico, com signos e representações historicamente construídas, que determinarão ao funcionamento cerebral diversas possibilidades, mobilizando o sujeito na realização de diferentes tarefas. Isto implica dizer que os esquemas cerebrais por si sós seriam incapazes de avançar para outros estágios mais elaborados sem a interação do indivíduo com grupos sociais e a mediação de adultos e crianças no processo do desenvolvimento. Entende-se que este processo não é, no entanto, linear, harmônico e homogêneo, pois é determinado pelo processo cultural constituído dialeticamente nas relações sociais que, do mesmo modo, as constituem.

Por essa condição, efetiva-se a constituição de um ser biológico em ser social, ou seja, na medida em que é apreendida a forma de desempenhar os papéis sociais, intrínsecos à sua condição de classe, etnia e de gênero, o indivíduo, em processo de socialização, se situa na estrutura social à qual pertence e age sobre ela redefinindo-a pelas experiências que vivencia.

Na perspectiva de Vygotsky (1989), esse processo de trocas e interações é fundamental para o desenvolvimento das funções psicológicas superiores. Portanto, é importante perceber que, embora os bebês se apropriem do que está estabelecido, ao mesmo tempo dão novos significados e, de forma sutil, apresentam o modo como se relacionam com o mundo.

Assim, a constituição da linguagem entre os bebês está associada ao lugar social que ocupam e às relações estabelecidas com o outro e com o meio, processo que deve ser viabilizado pela mediação do adulto, como forma de ampliar e garantir a comunicação dos pequeninos com o mundo. Isto significa que é preciso compreender como a criança se apropria de signos a partir do que já foi culturalmente construído por gerações anteriores. 
Bakhtin (1986) desenvolveu um importante estudo sobre como a consciência individual se apropria de signos sociais, ideologicamente construídos:

Os signos só emergem, decididamente, do processo de interação entre uma consciência individual e uma outra. E a própria consciência individual está repleta de signos. A consciência só se torna consciência quando se impregna de conteúdo ideológico (semiótico) e, consequentemente, somente no processo de interação social (BAKHTIN, 1986, p. 34).

Desta forma, passam a ser fundamentais a intencionalidade das ações pedagógicas e o olhar sensível do adulto no coletivo das creches, onde um número representativo de bebês passa grande parte de seus dias, num confinamento de regras e rotinas da instituição, e onde, por vezes, suas possibilidades de ampliação da linguagem e de emancipação das potencialidades humanas são pouco valorizadas. Daí serem imprescindíveis a troca e a interação verbal e afetiva entre todos os partícipes do contexto.

As crianças pequeninas, que estão no início de sua inserção no mundo externo (social) e que ainda dependem da interação dos adultos para a realização de suas necessidades básicas, têm uma linguagem repleta de significações e representações pelas quais podem possibilitar a compreensão dos desejos e sentimentos que estão expressando. É o início de um diálogo com o espaço socialmente organizado e com o grupo social a que pertencem, da mesma maneira que com os objetos que lhes são disponibilizados. As estratégias de comunicação utilizadas pelos bebês podem ser entendidas como fenômeno transformador do indivíduo em relação ao todo. É por meio do processo dialógico da linguagem com o mundo que eles se constituem e são constituidores um do outro na relação social.

O processo de constituição da linguagem entre os bebês, além de propiciar um salto qualitativo no desenvolvimento, também promove significativas ações entre eles. Essas ações subsidiam o processo de autoria das crianças pequeninas, possibilitando a convergência entre a interação com o concreto e a abstração das ideias por meio da relação dialógica, assumindo maiores dimensões no desenvolvimento e na interação do sujeito com o meio social. 
Compreender a linguagem dos bebês como elemento indispensável na interação e ação com as crianças implica reconhecer as estratégias de comunicação como precedentes, mas constituidoras da fala, e, portanto, imprescindíveis para a constituição humana.

Este olhar para as manifestações e para as estratégias de ação dos bebês nos oferece subsídios para compreender as crianças em idade inicial com mais profundidade. A linguagem passa a representar a entrada da criança no universo simbólico do mundo, razão pela qual, pensando no espaço da Educação Infantil, os adultos que participam desse processo dialógico devem estar atentos aos indicativos apresentados. Nessa direção, Oliveira (2002) assevera:

A criança constrói, assim, conhecimentos conforme estabelece relações que organizam e explicam o mundo. Isso envolve assimilar aspectos dessa realidade, apropriando-se de significados sobre a mesma, através de processos ativos de interação com outras pessoas e objetos, modificando ao mesmo tempo sua forma de agir, pensar e sentir (OLIVEIRA, 2002, p. 51).

Tomando como base esta compreensão, tem-se a linguagem como um processo social e culturalmente construído, isto é, os bebês constituem as formas de comunicação na relação que estabelecem entre si, com as outras crianças, com os adultos e com o próprio meio; portanto, a linguagem está impregnada dos valores socioculturais dos contextos em que atuam. No entanto, essa mesma linguagem, por eles manifestada, traz consigo uma carga de representação dos desejos e olhares sobre o universo, demonstrada para além das necessidades básicas.

Desse modo, percebi que o processo de socialização entre os bebês e os adultos deve considerar a dimensão interacionista das relações [...] "entre conhecimento de si e conhecimento do outro, construção de si e construção do outro" (MOLLO-BOUVIER, 2005, p.392), permitindo que a linguagem, manifestada por eles, expresse significados e sentidos no espaço da educação infantil, em situações sociais reais de enunciação, rompendo com a lógica adultocêntrica que tende a valorizar um único tipo de linguagem. Para tanto, torna-se fundamental considerar o papel da imaginação. Diferentemente do que estabelece o conhecimento hegemônico, a imaginação e a fantasia são constitutivas 
da realidade, conforme afirma Vygotsky (1996), ao considerar esse processo como alicerce da atividade criadora do homem.

Nas ações das crianças pequeninas, a imaginação e a fantasia se manifestam a partir das brincadeiras e da diversidade de elementos que lhes são oferecidos e possibilitam a ressignificação das ações. Embora a brincadeira simbólica se faça presente, com menor intensidade entre os bebês no primeiro ano de vida, já é possível perceber algumas nuanças dessas representações manifestadas e partilhadas por eles nas relações sociais que estabelecem.

Por esse aspecto, seria também possível abrir caminhos para a imaginação, para a criação e a sensibilidade, para a manifestação do espírito, como desvenda Benjamin (1992, p. 184), ao afirmar: "quanto mais profundo, ou seja, existente e real for o espírito, tanto mais ele é expresso e exprimível". É necessário que os sentidos se integrem profundamente ao meio e ao outro para que a intuição possa fluir, viabilizando cada vez mais a entrada dos bebês no mundo simbólico de nossa cultura, que se expressa pela linguagem em suas múltiplas dimensões, e não apenas pela fala e a escrita.

As práticas educativas para com os bebês, no contexto da creche, trazem consigo uma carga determinante no processo de valorização e legitimação da linguagem que constitui e se constitui entre os bebês, permitindo, inclusive, o início de um diálogo entre eles, as crianças maiores e os adultos, como forma de compreender as manifestações e interpretações que eles expressam.

\section{Algumas considerações}

O estudo dos autores anteriormente citados permitiu-me compreender como historicamente os bebês e a infância vêm sendo pensados na sociedade. Por mais que se percebam avanços em relação ao lugar social que a criança ocupa na sociedade atual, são constatadas diversas lacunas, principalmente no que concerne aos seus direitos de participação. A ausência da fala explicaria, talvez, a desconsideração com que são vistas suas ações. 
Embora se saiba que os bebês se apropriam da linguagem social, implica pensar também nas significações que os próprios atribuem à linguagem, ao simbolismo das ideias na relação com o mundo concreto. É importante perceber que a linguagem está associada aos seus fazeres sociais e culturais (às expressões peculiares de cada bebê), ouvindo, balbuciando, chorando, sorrindo, batendo palmas, olhando, tocando objetos (explorando o meio). Os bebês vão estabelecendo vínculos e se apropriando de formas de linguagem importantes para as suas relações sociais.

Seguindo os preceitos da pesquisadora Tristão (2006), mesmo nos casos em que as crianças vivenciam situações comuns em contextos comuns, as experiências serão sempre diferentes, únicas, pois são singulares. Assim, é determinante que se conheça cada menino e menina, considerando e garantindo sua alteridade (LAROSSA, 2001). A autora alerta que, mesmo havendo pesquisas acerca da linguagem dos bebês e, principalmente, sobre a infância, nem sempre os adultos se dedicam a considerar as manifestações das crianças, e dos bebês especificamente, por vezes submetendo-os às regras das instituições de educação infantil, limitadas a rotinas e a concepções preestabelecidas pelos adultos.

Partindo dos pressupostos da Sociologia da Infância, a linguagem entre os bebês é o meio que elas têm para manifestar a apropriação que fazem do mundo e da cultura, travando relações sociais, tornando-se sujeitos ativos, capazes de atuar com outros sujeitos de diferentes idades e com seus pares. É nessa sua interação com o mundo que os cerca, que o processo dialógico se manifesta e ganha importância, ao entender-se que a linguagem enunciada traduz, além de desejos e necessidades, acima de tudo seus próprios pontos de vista. E para que se rompa com a lógica adultocêntrica, é preciso, antes de tudo, compreender a infância como um período pleno, em que os sujeitos que a compõem são sujeitos de linguagem, para quem a fala e a escrita, embora fundamentais, não devem ser determinantes para que se conheçam melhor os modos de ser das crianças pequenas. Os bebês enunciam pela arte, pela emoção, pelo choro, pelo riso, pelo silêncio e assim constituem e se constituem na e pela linguagem. 


\section{Referências}

ARIÈS, Philippe. História social da criança e da família. 2. ed. Rio de Janeiro: Editora Guanabara, 1981.

ARIÈS, Philippe. Infanzia. In: Enciclodepia Einaudi, v.VII, Torino, Einaudi, 1979.

BAKHTIN, Mikhail. Marxismo e filosofia da linguagem. São Paulo: Hucitec, 1986.

BECCHI, Egle. Retórica da Infância. Revista Perspectiva. Florianópolis: NUP/CED: Editora da UFSC, n. 22, p. 63-95. ago./dez. 1994.

BENJAMIN, Walter. Sobre arte, técnica, linguagem e política. Tradução de Maria Luz Moita. Lisboa: Antropós, 1992.

BONDIOLI, Anna; MANTOVANI, Susanna. Manual de educação infantil: de o a 3 anos. 9. ed. Porto Alegre: ArtMed, 1998.

CHAMBOREDON, Jean Claude; PRÉVOT, Jean. O ofício da criança: definição social da primeira infância e funções diferenciadas da escola maternal. Cadernos de Pesquisa. São Paulo, n. 59, nov. p. 32-56. 1986.

DEL PRIORI, Mary. (Org.). Carla Bassanezi. História das mulheres no Brasil. São Paulo: Contexto, 1997.

FERREIRA, Maria Manuela. Salvar os corpos forjar a razão. Contributo para uma análise crítica da criança e da infância como construção social em Portugal. IIIE, Lisboa, 2000.

HOUAISS, Antônio. Houaiss: dicionário da língua portuguesa. 3. ed. Rio de Janeiro. Objetiva, 2009.

KUHLMANN Jr., Moyses. Infância e educação infantil: uma abordagem histórica. Porto Alegre: Mediação, 1998.

LARROSSA, Jorge. Pedagogia profana: danças, piruetas e mascaradas. 4. ed. Belo Horizonte: Autêntica, 2001.

MOLLO-BOUVIER, Suzanne. Transformação dos modos de socialização das crianças: uma abordagem sociológica. Educação e Sociedade. Campinas v. 26 n. 91, p. 337-712, maio./ago. 2005 . 
OLIVEIRA, Zilma Moraes Ramos de (Org.). Creches: crianças, faz de conta \& Cia. Petrópolis: Vozes, 2002.

PANOFSKY, Erwin. Significado nas artes visuais. Editora Perspectiva S. A. São Paulo. 1979.

PINTO, Manuel; SARMENTO, Manuel Jacinto. As crianças: contextos e identidades. Portugal: Centro de Estudos da Criança: Editora Bezerra, 1997.

PROUT, Alan. Reconsiderar a nova sociologia da infância: para um estudo multidisciplinar das crianças. Braga (Portugal): IEC 2004. Ciclo de Conferências em Sociologia da Infância. 2003/2004. Tradução: Helena Antunes. Digitalizado.

REIS, Magali. À imagem e semelhança: um estudo sobre a imagem da criança nas pinturas de Eliseu Visconti, Rego Monteiro, Tarsila do Amaral e Lasar Segall. 2007. Tese (Doutorado) - Universidade Estadual de Campinas - Faculdade de Educação - UNICAMP. Campinas/SP.

ROCHA, Eloisa Acires Candal. Diretrizes Educacionais pedagógicas para a Educação Infantil. In: FLORIANÓPOLIS. Diretrizes Educacionais pedagógicas para a Educação Infantil. Secretaria Municipal de Educação. Prefeitura Municipal de Florianópolis. Florianópolis, 2010.

SARMENTO, Manuel Jacinto. Gerações e alteridade: interrogações a partir da sociologia da infância. Educação \& Sociedade, v. 26, nº. 9, 2005.

TRISTÃO, Fernanda Carolina Dias. A sutil complexidade das práticas pedagógicas com bebês. In: MARTINS FILHO, A. J. et al. Infância plural: crianças do nosso tempo. Porto Alegre: Mediação, 2006.

VYGOTSKY, Lev Semyonovich. Obras escojidas. v. IV. Madrid: Visor, 1996.

VYGOTSKY, Lev Semyonovich. Pensamento e linguagem. 2. ed. São Paulo: Martins Fontes, 1989.

WARDE, Mirian Jorge. Repensando os estudos sociais de história da infância no Brasil. Revista Perspectiva. Florianópolis: v. 25, n. 1, p. 21-39, jan./jun. 2007. 
Recebido em: 18/11/2012 Aprovado em: 31/01/2013

Universidade do Estado de Santa Catarina - UDESC Programa de Pós-Graduação em Educação - PPGE Revista Linhas

Volume 14 - Número 27 - Ano 2013 revistalinhas@gmail.com 